\title{
Positive and negative patterning after CS preexposure in flavor aversion conditioning
}

\author{
DESWELL T. FORBES and PETER C. HOLLAND \\ University of Pittsburgh, Pittsburgh, Pennsylvania 15260
}

Three experiments examined rats' ability to discriminate a compound conditioned stimulus (CS) from the individual elements of that compound in a flavor aversion conditioning paradigm. In Experiment 1, presentations of a compound of sucrose and saline solutions were followed by lithium chloride injections, but presentations of those elements individually were nonreinforced (positive patterning). Conversely, in Experiments 2 and 3, presentations of the individual elements were followed by lithium chloride injection, but compound presentations were nonreinforced (negative patterning). The discriminations were acquired in all three experiments. In addition, all three experiments investigated the effects of preexposure of the discriminative stimuli on subsequent acquisition of the patterned discriminations. In positive patterning, preexposure had no measurable effect on the acquisition of responding (suppression) to the reinforced compound stimulus, but slowed the loss of suppression to the nonreinforced elements. In negative patterning, preexposure slowed the acquisition of suppression to the reinforced elements but had little effect on the loss of suppression to the nonreinforced compound.

The associative strength of a compound conditioned stimulus (CS) is typically described as the combined strengths of its individual elements. This simple assumption has made possible successful predictions concerning a large number of compound conditioning phenomena such as summation, blocking, and conditioned inhibition (e.g., Rescorla \& Wagner, 1972; Sutherland \& Mackintosh, 1971). In recent years, however, results from a number of experiments (e.g., Razran, 1965) have demonstrated that in many instances animals may treat a compound stimulus quite differently from its elements. Consequently, some researchers (e.g., Razran, 1965; Rescorla, 1972) have suggested that compound stimulus conditioning may involve some configural process or cue.

Evidence for configural conditioning has been found most frequently in experiments investigating patterned discriminations. In a positive patterning discrimination, a compound stimulus $(\mathrm{AB})$ is reinforced, but its individual elements ( $\mathrm{A}$ and $\mathrm{B}$ ) are nonreinforced. Animals have been found to master this discrimination (i.e., respond more to the com-

This article is based on a thesis submitted by the first author to the University of Pittsburgh in partial fulfillment of the requirements for the MS degree. This research was supported in part by U.S. Public Health Services Grants SO7 RR07084-11 and MH3138396. Thanks are due to the members of the first author's thesis committee, Harry Fowler, Donald McBurney, and Merle J. Moskowitz. Special thanks are also due to Robert T. Ross for his assistance in conducting Experiment 3 . The first author expresses his deepest gratitude to his mother, Margaretta, grandmother, Charity, and sister, Desalene, for their unselfish support in this endeavor. Requests for reprints should be sent to Deswell T. Forbes, Department of Psychology, University of Pittsburgh, Pittsburgh, Pennsylvania 15260. pound than to either of its individual elements) in a variety of conditioning situations, such as salivary conditioning in dogs (Pavlov, 1927; Woodbury, 1943), autoshaped pecking in pigeons (Rescorla, 1979), and discrete-trial barpressing in rats (Rescorla, 1972). Conversely, animals may be taught to inhibit responding to a compound stimulus but to respond to the individual elements presented separately (negative patterning). Again, successful negative patterning has been obtained in a number of preparations, for example, salivary conditioning in dogs (Pavlov, 1927; Woodbury, 1943), autoshaped pecking in pigeons (Rescorla, 1979), discrete-trial barpressing in rats (Rescorla, 1972), and eye-blink conditioning in rabbits (Whitlow \& Wagner, 1972).

The experiments reported here examined positive and negative patterning in a flavor aversion conditioning preparation. They were intended, first, to add to a small but rapidly growing literature of simultaneous flavor compound conditioning (e.g., Rescorla \& Cunningham, 1978) and, second, to develop a rapid and convenient procedure for studying patterned discriminations. Previously reported patterning studies have involved very lengthy training sequences, which may have discouraged finer analysis of patterned discriminations.

In addition, the present experiments examined the effects of stimulus preexposure on the acquisition of patterned discriminations. Previous studies on both conventional conditioning preparations (e.g., Rescorla, 1971) and flavor aversion conditioning (e.g., Best, 1975; Kalat \& Rozin, 1973) have shown that preexposure of a stimulus generally slows the acquisition of both conditioned excitation and inhi- 
bition to that stimulus. Similar preexposure effects have also been observed in conventional discrimination procedures (Halgren, 1974), but little is known about the effects of stimulus preexposure on discrimination training in flavor aversion conditioning.

Experiment 1 examined the effects of preexposing the compound stimulus, its elements, or neither stimulus on the acquisition of patterning. Experiments 2 and 3 examined the effects of discriminative stimulus preexposure on the establishment of negative patterning.

\section{EXPERIMENT 1}

\section{Method}

Subjects and Apparatus. Forty-eight naive male Sprague-Dawley rats, about 100 days old, were housed in individual cages $20 \times 25 \times$ $20 \mathrm{~cm}$ with Purina Rat Chow available ad lib. Solutions were presented in calibrated drinking tubes with stainless steel spouts. The rats lived in a constantly illuminated colony room in which all experimental manipulations were conducted.

Solutions. The solutions used were $.2 \mathrm{M} \mathrm{NaCl}(\mathrm{Na}), .1 \mathrm{M}$ sucrose (Suc), and a compound of the two (NaS), mixed so as to maintain the molarities of the individual solutions. In other experiments, these solutions were found to maintain their distinctiveness when compounded (Holland \& Forbes, 1980; Rescorla \& Cunningham, 1978). All solutions were prepared $12 \mathrm{~h}$ prior to their presentation and stored at room temperature.

Procedure. Prior to the experimental treatment, all rats were housed in their home cages for several weeks with food and water freely available. On the first experimental day, rats were randomly assigned to six groups $(\mathrm{N}=8)$ and fluid access was restricted.

During the first phase of the experiment, subjects were preexposed to the compound flavor stimulus (Groups CP and CU), the elements of the compound (Groups EP and EU), or neither the compound nor its elements (Groups NP and NU). Stimulus presentations were administered at 12 -h intervals; no other fluids were available during this or any other phase of the experiment. Subjects in Groups EP and EU received seven 10 -min presentations of $.2 \mathrm{M} \mathrm{NaCl}$ and seven $10-\mathrm{min}$ presentations of $.1 \mathrm{M}$ sucrose during alternate preexposure trials. Groups $\mathrm{CP}$ and $\mathrm{CU}$ received $10-\mathrm{min}$ presentations of tap water on each of the first seven trials and 10-min presentations of the NaS compound solution during the last seven trials of the preexposure phase. Groups NP and NU received 14 10-min presentations of tap water during this phase.

During three regularly scheduled drinking periods between preexposure trials 12 and 13 , three two-bottle tests evaluating preferences among all pairs of stimuli were administered. Data from these tests are not reported here.

The discrimination phase of the experiment began on the 15 th trial and continued for 10 three-trial cycles. Each cycle consisted of one 10-min presentation of the NaS compound, one 10-min presentation of $\mathrm{Na}$, and one 10-min presentation of Suc. As in the previous phase, the interval between each trial presentation was $12 \mathrm{~h}$. In the three experimental (paired) groups (EP, $C P$, and NP), each compound presentation was followed immediately by an interperitoneal injection of .3M lithium chloride $(\mathrm{LiCl})$ at $.5 \%$ body weight. Subjects in the three control (unpaired) groups (CU, EU, and NU) received identical injections, but delayed $4 \mathrm{~h}$ after each compound presentation. Thus, this phase was designed to establish conditioning to the compound (NaS), but not to its elements (Suc and $\mathrm{Na}$ ) in the three experimental groups (EP, CP, and NP). The three control groups (EU, CU, and NU) permitted us to determine whether changes in consumption of the various solutions in the experimental groups depended on NaS$\mathrm{LiCl}$ pairings.

Unless otherwise noted, the $\mathrm{p}<.05$ level of significance was used throughout these experiments.

\section{Results}

Preexposure. Consumption of each of the solutions increased over the course of preexposure but stabilized by the last four presentations. On those presentations, median consumption of the elements, compound, and water was $22.2,22.9$, and $20.0 \mathrm{ml}$ per presentation, respectively. There were no reliable differences in consumption among the groups at any point in preexposure (Kruskal-Wallis $\mathrm{Hs}<1.11$ ).

Discrimination training. Median fluid consumption during the discrimination phase of Experiment 1 after each of the three preexposure treatments is shown in Figure 1. In all three experimental groups, consumption of the reinforced NaS compound decreased over the course of training; by the last 4 cycies, rats in each experimental group consumed less $\mathrm{NaS}$ than rats in the corresponding unpaired control group (Mann-Whitney Us $=0$ ). Consumption, individually, of the nonreinforced elements, $\mathrm{Na}$ and Suc, also decreased initially in the experimental groups, presumably reflecting conditioning established to those elements on previous reinforced NaS trials. But, by the last 4 cycles of discrimination training, rats in all three experimental groups showed successful patterning; that is, they consumed more of both Suc (Wilcoxon $\mathrm{Ts}=0$ ) and $\mathrm{Na}(\mathrm{Ts}<1.5)$ than of the reinforced NaS compound. No such preferences were found in the control groups ( $\mathrm{Ts}>6$ ).

Flavor preexposure slowed acquisition of the discrimination. Although there were no differences among the three experimental groups in NaS consumption on any trial block, by the last four cycles significant differences in consumption of both Suc $(\mathrm{H}=6.21)$ and $\mathrm{Na}(\mathrm{H}=6.01)$ were evident. Multiple comparison analyses (Hollander \& Wolfe, 1973, p. 124) showed that consumption of both Suc and $\mathrm{Na}$ was greater in Group NP than in Group EP; no other comparisons were reliable. Consumption of $\mathrm{NaS}, \mathrm{Na}$, and Suc did not differ among the three control groups $(\mathrm{Hs}<1.22)$.

\section{Discussion}

The simplest demonstration of positive patterning requires that an organism respond to a compound while withholding responding to the elements of that compound. Experiment 1 provided such a demonstration. Initially, rats consumed comparable amounts of $\mathrm{Na}$, Suc, and NaS. But consumption of the reinforced compound decreased throughout discrimination training, whereas after an initial decline, consumption of the nonreinforced elements increased or stabilized.

Preexposure of the element stimuli retarded the acquisition of positive patterning. This finding is consistent with previous studies, which reported that preexposure slowed the acquisition of nonpatterned discriminations (e.g., Halgren, 1974). Somewhat surprisingly, preexposure did not affect acquisition of suppression to the reinforced compound solution, even though previous experiments using the same 


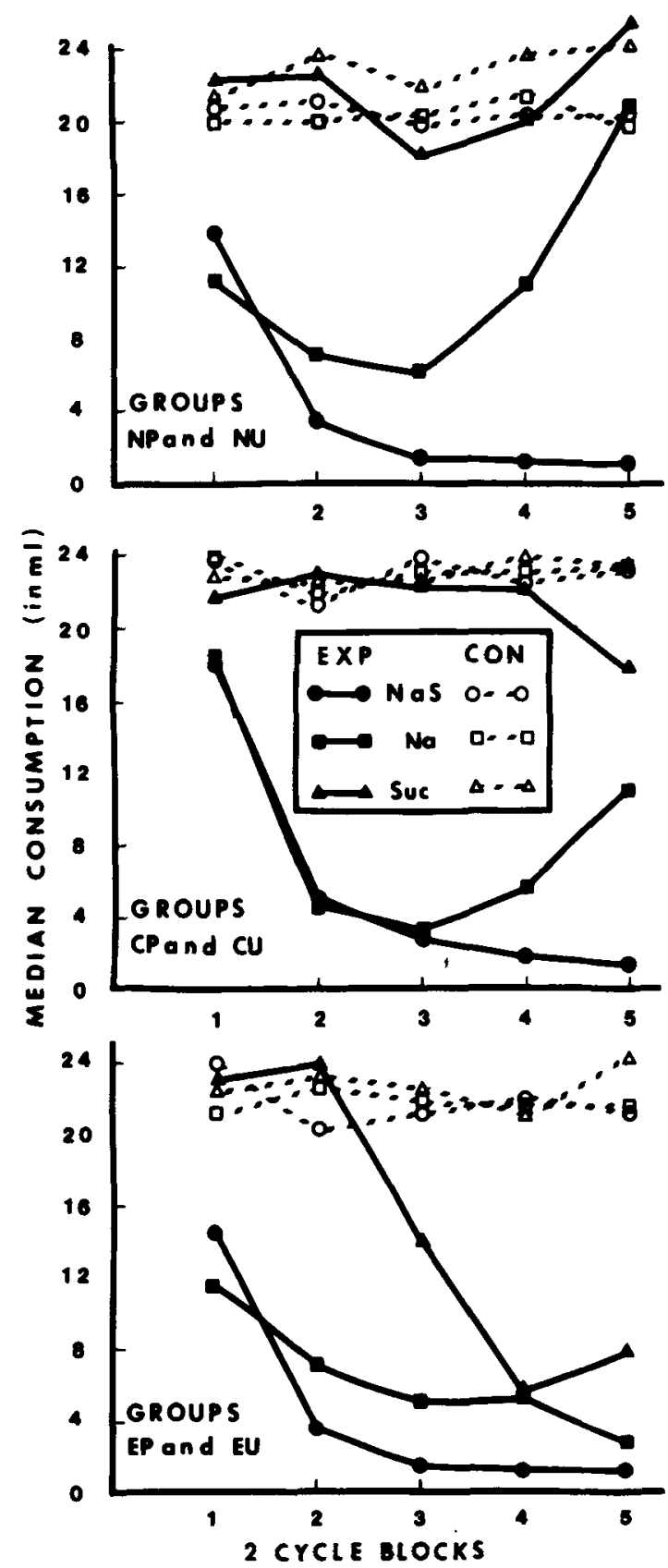

Figure 1. Median consumption of reinforced compound $\mathrm{NaS}$ and nonreinforced elements $N \mathfrak{a}$ and Suc during discrimination training in Experiment 1. NaS = saline + sucrose compound, $\mathrm{Na}=$ saline, Suc $=$ sucrose.

stimuli and preexposure procedures (Holland \& Forbes, 1980) found element preexposure to slow nondiscriminative conditioning of a reinforced compound solution. Instead, differences in discrimination acquisition among the experimental groups were largely the result of differences in the loss of suppression to the nonreinforced elements, a pattern also observed by Halgren (1974). One possible explanation for this absence of a preexposure effect on acquisition to the compound is that reduced loss of suppression to the elements resulted in less generalized extinction of the compound, which in turn masked any retardation of conditioning to the compound.

The occurrence of positive patterning does not in itself demand a configural process or cue. Kamin and Idrobo (1978) noted that weak or subthreshold responding to the elements might sum to produce considerable responding to the compound. They noted further, however, that observation of increases in responding to the compound and decreases in responding to the elements simultaneously within a series of conditioning trials would be incompatible with such a summation account. It is worth noting that over cycle blocks 2 through 5 of discrimination training, Group NP showed reliable increases in the consump tion of both $\mathrm{Na}$ and $\mathrm{Suc}$, but a significant decrease in consumption of $\mathrm{NaS}(\mathrm{Ts}<5)$.

Of course, selected data from a single group do not provide unequivocal evidence for a configural process over that of summation. Consequently, in Experiment 2, rats were trained in a negative patterning discrimination, which has frequently been assumed to require some configural process for solution. Rats were trained to suppress consumption of the elements of a compound but not of the compound itself. As in Experiment 1, the effects of preexposure on the acquisition of the discrimination were assessed.

\section{EXPERIMENT 2}

\begin{abstract}
Method
Subjects and Apparatus. The subjects were 48 male 100-day-old Sprague-Dawley rats. The apparatus and maintenance of the subjects were the same as in Experiment 1.

Procedure. Preexposure procedures were identical to those of Experiment 1: Groups CP and CU first received seven 10-min presentations of tap water and then seven 10 -min presentations of the NaS compound; Groups EP and EU received seven 10-min presentations of each of the individual $\mathrm{Na}$ and Suc elements; and Groups NP and NU received 14 presentations of tap water. All rats then received 3 cycles of discrimination training. Each cycle consisted of four 10-min presentations of the compound (NaS) and a single 10-min presentation of each element ( $\mathrm{Na}$ and Suc). In Groups CP, EP, and NP, each element presentation was followed immediately by injection of $.3 \mathrm{M} \mathrm{LiCl}(.5 \%$ body weight); $\mathrm{LiCl}$ injections were delayed until $4 \mathrm{~h}$ after element presentations in Groups CU, EU, and NU. As in Experiment 1, all stimulus presentations occurred at 12 -h intervals.
\end{abstract}

\section{Results and Discussion}

Preexposure. As in Experiment 1, fluid consumption gradually increased during the preexposure phase, stabilizing by the last four trials. Median consumption of the elements, the compound, and water solutions was $17.8,22.4$, and $15.0 \mathrm{ml}$, respectively, over those trials. A Kruskal-Wallis test showed that consumption differed under the three preexposure conditions $(\mathrm{H}=$ 25.61); subsequent multiple comparisons showed that consumption of the compound was greater than that of either the elements or water, which did not differ from each other. 
Discrimination training. Median fluid consumption during the discrimination phase of Experiment 2 is shown in Figure 2. Consumption of the reinforced elements, $\mathrm{Na}$ and Suc, decreased over the course of

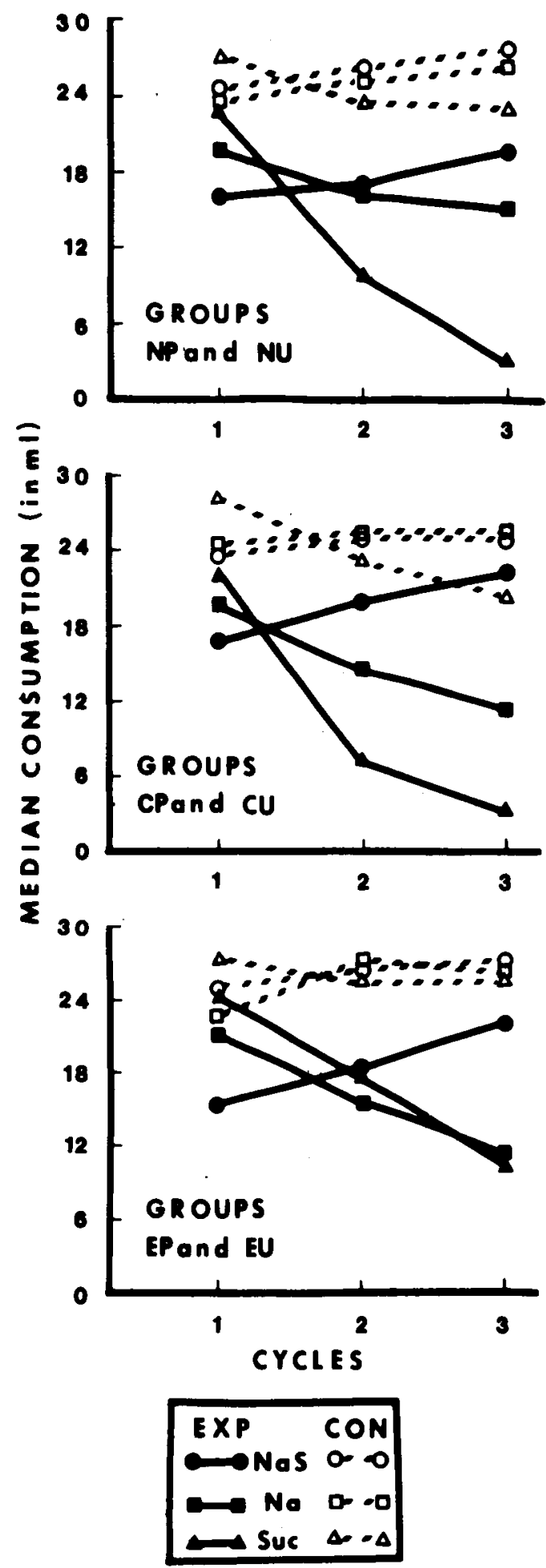

Figure 2. Consumption of reinforced elements, $\mathrm{Na}$ and Suc, and nonreinforced compound, $\mathrm{NaS}$, during discrimination training in Experiment 2. $\mathrm{NaS}=$ saline + sucrose compound, $\mathrm{Na}=$ saline, Suc $=$ sucrose. discrimination training in all rats in the experimental groups; by the last cycle, rats in each of those groups consumed less of both $\mathrm{Na}$ and Suc (Us $<11,0$, respectively) than rats in the corresponding control groups. Similarly, first-trial consumption of the nonreinforced NaS compound in each of the experimental groups was also lower than that in the corresponding control groups (Us $<15$ ), presumably reflecting conditioning established to $\mathrm{Na}$ and Suc on previous reinforced element trials. Over the course of training, however, consumption of the nonreinforced $\mathrm{NaS}$ compound recovered somewhat in the experimental groups: In the last cycle, rats in all three experimental groups consumed significantly more of the compound $\mathrm{NaS}$ than of Suc (Ts $<1)$ and numerically more of $\mathrm{NaS}$ than of $\mathrm{Na}$, although this latter difference was reliable $(T s<6)$ only in Groups EP and CP. No reliable preferences were found in any of the control groups (Ts $>14$ ). Thus, successful negative patterning developed over the course of the discrimination.

The effects of preexposure on the acquisition of negative patterning were minimal. Only consumption of Suc differed reliably among the experimental groups $(H=9.63)$. Multiple comparison tests showed that consumption of Suc was greater in Group $E$ than in either of the other groups, which did not differ reliably.

Experiment 2 further demonstrated the ability of rats to respond differentially to a flavor compound and its elements. Consumption of the nonreinforced compound increased during discrimination training, while consumption of the reinforced elements decreased. This pattern of data is not consistent with a strictly summative view of compound conditioning effects, but is compatible with the assumption that a compound possesses (or acquires) a configural cue in addition to its isolable elements.

\section{EXPERIMENT 3}

Stimulus preexposure had reliable effects only on acquisition of suppression to the sucrose element in Experiment 2. Experiment 3 attempted to magnify the effects of preexposure on the acquisition of negative patterning by presenting more preexposure trials, increasing group size, and using slightly different concentrations of the sucrose and saline solutions. The data of both Experiments 1 and 2 suggested that the NaS compound was perceptually more like the $\mathrm{Na}$ solution than like the Suc solution; reinforcement of the NaS compound in Experiment 1 resulted in more suppression to $\mathrm{Na}$ than to Suc; the slower acquisition of suppression to the reinforced $\mathrm{Na}$ than to Suc in Experiment 2 may have been the consequence of greater generalization from the nonreinforced compound. In Experiment 3, an attempt was made to increase the relative salience of Suc to make the discrimination of compound from elements more symmetrical. 
Since there were no reliable differences in consumption of the various solutions among the control groups in Experiments 1 and 2, no control groups were included in Experiment 3. Also, only element- and nopreexposure conditions were included.

\section{Method \\ Subjects and Apparatus. The subjects were 24 female 140-day-old Sprague-Dawley rats. All rats had been previously exposed to auditory, visual, and food stimuli under conditions of food depri- vation; their assignment to groups in the present experiment was orthogonal to their earlier treatment. The apparatus and main- tenance of the subjects were the same as in Experiments 1 and 2 except that the colony room was illuminated $14 \mathrm{~h}$ each day \\ Procedure. Rats were first adapted to the water-deprivation schedule to be used in this experiment: tap water was presented for 10 min every $12 \mathrm{~h}$ for 1 week. Then rats in Group $\mathrm{E}(\mathrm{n}=12)$ received 10 10-min presentations each of $.8 \mathrm{M} \mathrm{NaCl}(\mathrm{Na})$ and $.125 \mathrm{M}$ sucrose (Suc), randomly intermixed, at 12 -h intervals. Rats in Group $N(n=12)$ received 2010 -min presentations of tap water in this phase. Next, all rats received 3 cycles of discrimi- nation training similar to that of Experiment 2. Each cycle consisted of one 10-min presentation of each element followed immediately by injection of $.3 \mathrm{M} \mathrm{LiCl}(.5 \%$ body weight) and four $10-\mathrm{min}$ nonreinforced presentations of a compound of the two solutions (NaS) mixed so as to maintain the molarities of the element solu- tions. Stimulus presentations occurred at $12-\mathrm{h}$ intervals, $1 \mathrm{~h}$ after illumination of the colony room and $1 \mathrm{~h}$ before the lights were extinguished.}

\section{Results and Discussion}

Preexposure. Consumption of the preexposed solutions was maintained at the same level throughout the preexposure phase. Mean median consumption over the last three trials was $19.7 \mathrm{ml}$ in Group $\mathrm{E}$ and $11.2 \mathrm{ml}$ in Group $\mathrm{N}$; this difference was reliable $(\mathrm{U}=13)$.

Discrimination training. Median fluid consumption during the discrimination phase of Experiment 3 is shown in Figure 3. By the final cycle, rats in both groups consumed more of the NaS compound than of either the Na or Suc elements individually (Ts $<1.5$ ). During that cycle, there was no reliable difference in consumption of the nonreinforced $\mathrm{NaS}$ compound between the two groups (Mann-Whitney, $z=1.30$ ) but consumption of both the reinforced Suc and $\mathrm{Na}$ solutions was greater in Group $E$ than in Group $N$ ( $\mathrm{zs}=4.07$ and 1.91 , respectively). Thus, by the end of training, the negative patterning discrimination was superior in Group $\mathrm{N}$, which had no preexposure of the discriminative stimuli.

As in Experiment 1, the effects of preexposure were most obvious in consumption of the element solutions. It is worth noting that consumption of Suc and $\mathrm{Na}$ did not differ reliably $(\mathrm{zs}=1.50, .26)$ between the groups on the initial presentation of those elements. Thus, greater consumption of those elements in Group $\mathrm{E}$ at the end of training was probably not merely the result of reduced neophobia. Note also that during the first cycle, consumption of the nonreinforced compound solution was greater in Group $\mathrm{E}$ than in Group $\mathrm{N}(\mathrm{z}=3.20)$. This difference

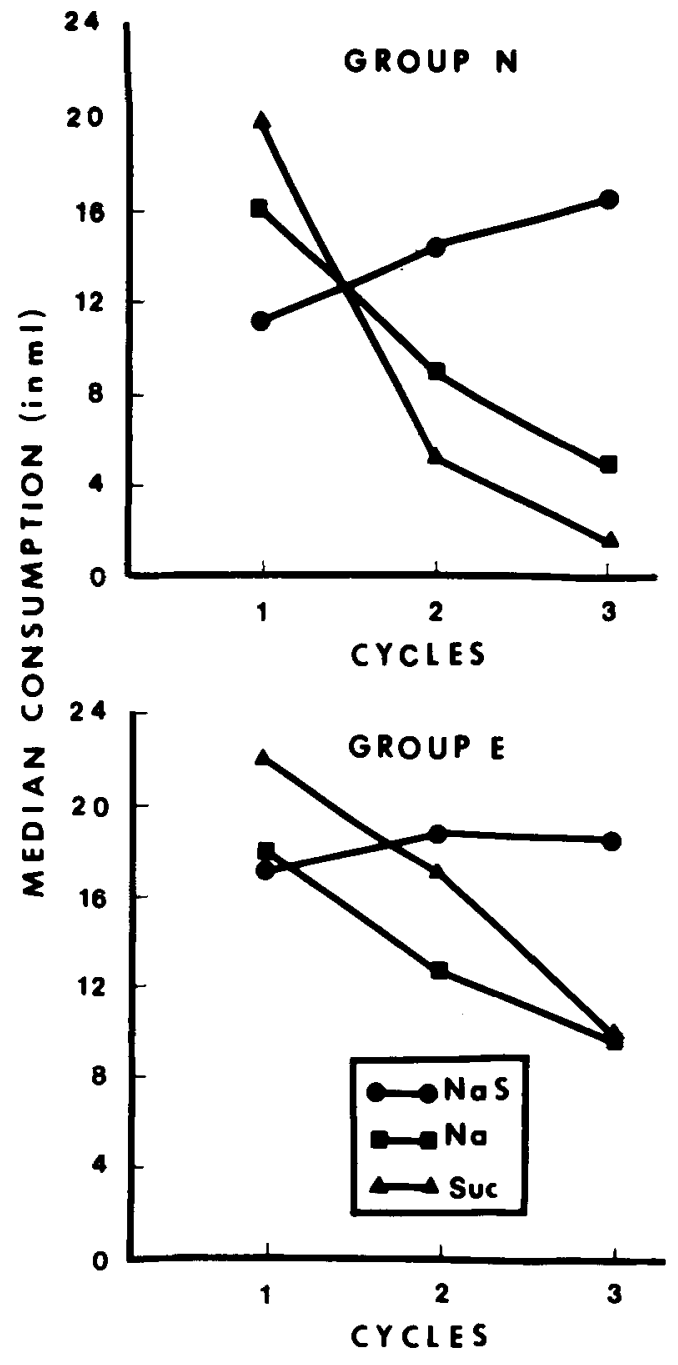

Figure 3. Consumption of reinforced elements, $\mathrm{Na}$ and Suc, and nonreinforced compound, $\mathrm{NaS}$, during discrimination training in Experiment 3. $\mathrm{NaS}=$ saline + sucrose compound, $\mathrm{Na}=$ saline, Suc $=$ sucrose.

probably reflects the greater conditioning of the elements in Group $\mathrm{N}$ during that cycle (compound presentations occurred only after one or both of the individual elements had been reinforced in that cycle).

\section{GENERAL DISCUSSION}

In all three experiments, rats learned to respond differentially to a compound and its elements in a flavor aversion conditioning preparation. In Experiment 1 , rats showed more suppression of consumption of a reinforced compound flavor stimulus than of either of its nonreinforced elements. Similarly, in Experiments 2 and 3, rats suppressed consumption of the separately reinforced elements more than consumption of the nonreinforced compound. The discrimination training procedures were sufficiently sensitive to detect detrimental effects of stimulus preexposure, as observed with nonpatterned discrimi- 
nation procedures in other preparations (e.g., Halgren, 1974). Furthermore, acquisition of the patterned discriminations was very rapid relative to the speed of acquisition reported in other preparations (e.g., Rescorla, 1972; Whitlow \& Wagner, 1972; Woodbury, 1943).

Although the present data do not specifically address the mechanisms of patterned discrimination acquisition, the solution of negative patterning problems implicates the involvement of some configural cue or process (e.g., Razran, 1965; Rescorla, 1972). At the same time, the occurrence of responding to the nonreinforced elements after reinforcement of the compound in Experiment 1 and of responding to the nonreinforced compound after element reinforcement in Experiments 2 and 3 shows that the elements were in fact contained and isolable within the compound stimulus. All in all, the results of the present experiments indicate that flavor aversion conditioning is an appropriate, convenient preparation for investigating patterned discriminations.

\section{REFERENCES}

Best, M. R. Conditioned and latent inhibition in taste aversion learning: Clarifying the role of learned safety. Journal of Experimental Psychology: Animal Behavior Processes, 1975, 1, 97-113.

Halgren, C. R. Latent inhibition in rats: Associative or nonassociative? Journal of Comparative and Physiological Psychology, 1974, 86, 74-78.

Holland, P. C., \& Forbes, D. T. Effects of compound or element preexposure on compound flavor aversion conditioning. Animal Learning \& Behavior, 1980, 8, 199-203.

Kalat, J. W., \& Rozin, P. "Learned safety" as a mechanism in long-delay taste aversion learning in rats. Journal of Comparative and Physiological Psychology, 1973, 83, 198-207.

Kamin, L. J., \& Inrobo, F. Configural conditioning in CER: A possible artifact. Animal Learning \& Behavior, 1978, 6, 290-293.

Pavlov, I. P. Conditioned reflexes. Oxford, England: Oxford University Press, 1927.

Razran, G. H. S. Empirical codifications and specific theoretical implications of compound-stimulus conditioning: Perception. In W. F. Prokasy (Ed.), Classical conditioning. New York: Appleton-Century-Crofts, 1965.

Rescorla, R. A. Summation and retardation tests of latent inhibition. Journal of Comparative and Physiological Psychology, 1971, 75, 77-81.

Rescorla, R. A. "Configural" conditioning in discrete-trial bar-pressing. Journal of Comparative and Physiological Psychology, 1972, 79, 307-317.

Rescorla, R. A. Aspects of the reinforcer learned in secondorder Pavlovian conditioning. Journal of Experimental Psychology: Animal Behavior Processes, 1979, 5, 79-95.

Rescorla, R. A., \& Cunningham, C. L. Within compound flavor associations. Journal of Experimental Psychology: Animal Behavior Processes, 1978, 4, 267-275.

Rescorla, R. A., \& Wagner, A. R. A theory of Pavlovian conditioning: Variations in the effectiveness of reinforcement and nonreinforcement. In A. H. Black \& W. F. Prokasy (Eds.), Classical conditioning II: Current research and theory. New York: Appleton-Century-Crofts, 1972.

Suthe Rland, N. S., \& Mackintosh, N. J. Mechanisms of animal discrimination learning. New York: Academic Press, 1971.

Whitlow, J. W., \& Wagner, A. R. Negative patterning in classical conditioning: Summation of response tendencies to isolable and configural compounds. Psychonomic Science, 1972, 27, 299-301.

Woodbury, C. B. The learning of stimulus patterning by dogs. Journal of Comparative Psychology, 1943, 35, 29-40.

(Received for publication October 31, 1979; revision accepted July 22,1980 .) 